\title{
The Narrative Model of Therapeutic Change: An Exploratory Study Tracking Innovative Moments and Protonarratives Using State Space Grids
}

\author{
Tiago Bento \\ Institute of Higher Education of Maia and the University of Aveiro, Aveiro, Portugal \\ António P. Ribeiro \\ School of Psychology, University of Minho, Braga, Portugal
}

João Salgado and Inês Mendes

Institute of Higher Education of Maia and the Center of Psychology, Faculty of Psychology and Education Sciences, The University of Porto, Porto, Portugal

\author{
Miguel M. Gonçalves \\ School of Psychology, University of Minho, Braga, Portugal
}

\begin{abstract}
Despite the popularity of narrative approaches to the change in psychotherapy, a better understanding of how narrative transformation facilitates therapeutic change is needed. Research on innovative moments (IMs) has explored how IMs in psychotherapy evolve over time. We expand on past studies by exploring how IMs become aggregated in narrative threads, termed protonarratives, which come to constitute an alternative self-narrative at the conclusion of therapy. The results suggest that the good outcome case had a different pattern of IM integration within protonarratives, revealing greater flexibility than the poor outcome case. These results support the heuristic value of the concept of the protonarrative.
\end{abstract}

Despite the growing popularity of narrative approaches to psychotherapy (Gonçalves \& Stiles, 2011), one review concluded that "narrative approaches lack a theory that explains adequately how the reworking of narratives brings about changes and how a client's various narratives are

Received 12 June 2012; accepted 4 November 2012.

The authors are grateful to Leslie Greenberg and Lynne Angus from York University (Toronto, Canada) for allowing them to use the transcripts from the York I Depression Project.

This article was supported by the Portuguese Foundation for Science and Technology (FCT) via grants PTDC/PSIPCL/121525/2010 (Ambivalence and unsuccessful psychotherapy, 2012-2015) and PTDC/PSI-PCL/103432/2008 (Decentering and Change in Psychotherapy) and by Ph.D. grants SFRH/BD/46189/2008 and SFRH/BD/48266/2008.

Address correspondence to Miguel M. Gonçalves, School of Psychology, University of Minho, Braga, Portugal. E-mail: mgoncalves@psi.uminho.pt 
integrated" (Meier, 2002, from abstract). In fact, although the characteristics of initial problematic self-narratives have been explored (Dimaggio \& Semerari, 2001; Dimaggio et al., 2003; Lysaker \& Lysaker, 2006), the processes by which rigid self-narratives present at the beginning of therapy are replaced by more flexible, enriching self-narratives toward the end of therapy have remained largely unexplored. In this article we consider self-narratives to be overarching life stories that integrate meanings people attribute to their everyday life situations and provide them with a sense of self-identity (McAdams, 1996; Neimeyer, 2004) and we study their transformation across psychotherapy.

\section{THE NARRATIVE MODEL OF THERAPEUTIC CHANGE}

One possibility that has received increasing empirical support is that the emergence and expansion of narrative innovations (termed innovative moments, or IMs; Gonçalves, Matos, \& Santos, 2009) are at the centre of the process of transformation of clients' self-narratives in psychotherapy. IMs refer to micro-level autobiographical memories (see Singer, Blagov, Berry, \& Oost, 2013) of particular thoughts, feelings, and actions that are narrated within psychotherapy and are different from the ones that characterize the problematic self-narratives. The key idea is that therapeutic conversation attributes meaning to the IMs, expanding them and facilitating their aggregation in alternative narrative threads. In this process, IMs become self-defining memories (Singer et al., 2013) in the sense that they become constitutive of clients' sense of self-identity. Several studies have shown that IMs occur in different models of brief psychotherapy (Gonçalves, 2012; Gonçalves et al., 2012; Matos, Santos, Gonçalves, \& Martins, 2009; Mendes et al., 2010; Ribeiro, Gonçalves, \& Ribeiro, 2009). These studies have also demonstrated that five categories of IMs can be reliably identified in the context of psychotherapy by means of the innovative moments coding system (IMCS; Gonçalves et al., 2011) as follows: action, reflection, protest, reconceptualization, and performing change. The definitions and examples of these IMs are presented in Table 1. Studies that have identified IMs and tracked their development in therapy have consistently concluded that action, reflection, and protest IMs emerge in both good- and poor-outcome cases in the initial phase of therapy and remain present throughout therapy. Reconceptualization and performing change IMs tend to appear in good-outcome cases during the working phase of therapy and become increasingly frequent in the final phase. These last IMs are infrequent, or even absent, in poor-outcome cases.

Although these studies highlight that IMs are present in therapy regardless of the therapeutic model, it remains to be explored how IMs are sustained and expanded on, allowing a transformation of the previously dominant problematic self-narrative into an alternative narrative in successful therapy. In a previous study, it was suggested that IMs organize themselves according to their thematic content in provisional narrative plots termed protonarratives (Ribeiro, Bento, Gonçalves, \& Salgado, 2010; Ribeiro, Bento, Salgado, Stiles, \& Gonçalves, 2011).

Protonarratives are defined as recurrent themes that aggregate IMs of several types (e.g., action, reconceptualization) in narrative threads that are not yet fully developed self-narratives (see Ribeiro et al., 2010). In this sense, they integrate the self-defining memories expressed in IMs in narrative scripts (Singer et al., 2013) that express new potential narrative frameworks for behaving, thinking, and feeling that contrast with the problematic macro-level self-narratives. As they are addressed in therapeutic dialogues, these protonarratives may be abandoned or instead 
TABLE 1

IMs Contents and Examples

Action IMs

- New coping behaviours facing anticipated or existent obstacles

- Effective resolution of unsolved problem(s)

- Active exploration of solutions

- Restoring autonomy and self-control

- Searching for information about the problem(s)

Creating distance from the problem(s)

- Comprehension: reconsidering causes of problem(s) and/or awareness of effects

- New problem formulations

- Adaptive self-instructions and thoughts

- Intention to fight demands of problem(s), references of self-worth, and/or feelings of well-being

Centred on the change

- Therapeutic process: reflecting about the therapeutic process

- Change process: considering process and strategies; implemented to overcome problem(s); references of self-worth and/or feelings of well-being (as consequences of change)

- New positions: references to new/emergent identity versions in face of the problem(s)

Criticising the problem $(s)$

- Repositioning oneself toward the problem(s)

Emergence of new positions

- Positions of assertiveness and empowerment
C: Yesterday, I went to the cinema for the first time in months!

\section{Reflection IMs}

C: I realise that what I was doing was just not humanly possible because I was pushing myself and I never allowed myself any free time, uh, to myself ... and it's more natural and more healthy to let some of these extra activities go ...

C: I believe that our talks, our sessions, have proven fruitful, I felt like going back a bit to old times, it was good, I felt it was worth it.

\section{Protest IMs}

C: What am I becoming after all? Is this where I'll be getting to? Am I going to stagnate here!?

C: I am an adult and I am responsible for my life, and, and, I want to acknowledge these feelings and I'm going to let them out! I want to experience life, I want to grow and it feels good to be in charge of my own life.

Reconceptualization IMs

- Reconceptualization always involves two dimensions: - Description of the shift between two positions (past and present)

○ The process underlying this transformation
C: You know ... when I was there at the museum, I thought to myself, "You really are different ... . A year ago you wouldn't be able to go to the supermarket!" Ever since I started going out, I started feeling less depressed ... It is also related to our conversations and changing jobs ...

T: How did you have this idea of going to the museum?

C: I called my Dad and told him, "We're going out today!"

T: This is new, isn't it?

C: Yes, it's like I tell you ... I sense that I'm different 
TABLE 1

IMs Contents and Examples (continued)

\begin{tabular}{|c|c|}
\hline Contents & Examples \\
\hline \multicolumn{2}{|c|}{ Performing Change IMs } \\
\hline $\begin{array}{l}\text { - Generalisation into the future and other life } \\
\text { dimensions of good outcomes }\end{array}$ & $\begin{array}{l}\text { T: You seem to have so many projects for the future } \\
\text { now! }\end{array}$ \\
\hline $\begin{array}{l}\text { - Problematic experience as a resource to new situations } \\
\text { - Investment in new projects as a result of change } \\
\text { process }\end{array}$ & $\begin{array}{l}\text { C: Yes, you're right. I want to do all the things that were } \\
\text { impossible for me to do while I was dominated by } \\
\text { depression. I want to work again and to have the time }\end{array}$ \\
\hline $\begin{array}{l}\text { - Investment in new relationships as a result of change } \\
\text { process }\end{array}$ & $\begin{array}{l}\text { to enjoy my life with my children. I want to have } \\
\text { friends again. The loss of all the friendships of the }\end{array}$ \\
\hline - Performance of change: new skills & past is something that still hurts me really deeply. I \\
\hline - Re-emergence of neglected or forgotten self versions & $\begin{array}{l}\text { want to have friends again, to have people to talk to, } \\
\text { to share experiences, and to feel the complicity in my } \\
\text { life again. }\end{array}$ \\
\hline
\end{tabular}

Note: From Gonçalves et al. (2011). Adapted with permission. IMs = innovative moments.

evolve into more complex narrative plots that eventually become alternative self-narratives. For instance, consider a client's problematic self-narrative focused on lack of self-worth. At the beginning of therapy, this client may express difficulties in accepting his or her own limitations and narrate life episodes that reflect excessive perfectionism in work-related tasks and frequent worries concerning other people's thoughts about his or her performance in social roles (the problematic self-narrative). As a consequence of successful treatment, this client may start narrating thoughts that express self-acceptance and recognition of his or her own competencies (reflection IMs), protesting other peoples' lack of recognition of his or her needs (protest IMs) and expressing assertive behaviors towards others (action IMs). Taken together, these IMs reflect a protonarrative that is focused on a renewed sense of self-worth and affirmation of one's own identity, which is in contrast to the assumptions of the problematic self-narrative. Simultaneously, this client may also narrate an increased comprehension of other peoples' behavior toward him or her and show forgiveness (reflection IMs). As a consequence, the client may try to reconcile and reconnect with specific people by inviting them to spend time together and adjusting his or her own behavior in the relationships (action IMs). These IMs together express a protonarrative that we could globally term reconciliation. These two protonarratives contain narrative elements that may come to constitute an alternative self-narrative because they comprise a new set of assumptions that are different from those of the problematic self-narrative. Thus, the alternative self-narrative at the end of therapy can be one or the other, or even a combination of both. In sum, IMs would be the micro-level of narrative organization; protonarratives, as thematic organization of IMs that potentially lead to new self-narratives, the meso-level; and the self-narrative (problematic or alternative), the macro-level.

Therefore, we propose that we can conceptualize each IM as having two related dimensions-process (e.g., action, protest) and content (i.e., the theme that emerges)—which allows us to infer a given protonarrative. As protonarratives successfully develop in therapy, they will become more diversified in their content and in the IMs they contain. Moreover, previous research (Ribeiro et al., 2011) suggested that the protonarratives that emerge during treatment may interact. Our preliminary studies (Ribeiro et al., 2011) suggested that in successful therapy, 
one of the protonarratives that occurs during treatment will become increasingly central. It will occupy more time in sessions and will also show more diverse types of IMs.

\section{RESEARCH FOCUS}

Two main features of narrative change appear to be critical and will be targeted in this study. On one hand, the development of narrative flexibility (versus rigidity) is associated with adaptive narrative building and therefore is thought to be a key process in therapeutic change (Hermans, 2006; Lysaker \& Lysaker, 2006). On the other hand, narrative integration or coherence (versus fragmentation) is considered a fundamental feature of adaptive self-narratives, and thus therapeutic change must also involve this process (Neimeyer, 2004; Singer \& Rexhaj, 2006). In this study, by analyzing how flexibility and integration evolve on a session-by-session basis, we aim to explore the process of constructing alternative self-narratives throughout treatment.

\section{METHOD}

\section{Clients}

Clients participated in the York I Depression Study (Greenberg \& Watson, 1998). This study was originally focused on major depressive disorder, and the clients were randomly assigned to one of two different treatments: emotion-focused therapy (EFT) or client-centered therapy (CCT). Here, we analyze two cases (one good outcome and one poor outcome) randomly chosen from the EFT sample previously analyzed with the IMCS (Mendes et al., 2010).

The clients were classified with the Reliable Change Index (RCI; see Jacobson \& Truax, 1991; McGlinchey, Atkins, \& Jacobson, 2002) analysis of the Beck Depression Inventory (BDI; Beck, Steer, \& Garbin, 1988) for pre- and posttest change scores. According to this analysis, one client was classified as meeting the criteria for being recovered (i.e., passed both a BDI cut-off score of 11.08 and RCI criteria) and the other client was classified as unchanged (i.e., has not passed both the BDI cut-off score of 11.08 and the RCI criteria) at treatment termination. More specifically, the pre-post BDI scores for the good-outcome case were 25 and 3, whereas for the poor-outcome case, the BDI scores were 24 and 18.

\section{Good Outcome Case-Lisa}

Lisa (see Angus, Goldman, \& Mergenthaler, 2008, for the analysis of the same case from different perspectives; see also Gonçalves, Mendes, Ribeiro, Angus, \& Greenberg, 2010) was a 27-year-old married woman who had two school-aged children at the time of her participation in the York I Depression Study (Greenberg \& Watson, 1998). She described herself as being from a working-class background, and she was not employed at the beginning of treatment. However, she had secured part-time employment by the end of treatment. Lisa met the criteria for inclusion in the study on the basis of her diagnosis of major depressive disorder, as assessed by the structural clinical interview for the DSM-III-R (Spitzer, Williams, Gibbons, \& First, 1989). Lisa was randomly assigned to EFT and was seen for 15 sessions. Lisa reported feelings of sadness, 
guilt, and resentment toward her family and was unable to articulate the roots of her depressed feelings prior to entering therapy.

\section{Poor Outcome Case-Ralph}

Ralph was a 43-year-old married man with a bachelor's degree who was unemployed at the time of his participation in the York I Depression Study (Greenberg \& Watson, 1998). Ralph met the criteria for inclusion in the study on the basis of his diagnosis of major depressive disorder, as assessed using the structural clinical interview for the DSM-III-R (Spitzer et al., 1989). Ralph was randomly assigned to EFT and was seen for 17 sessions. He reported feelings of despair, hopelessness, and resentment mainly related to his unemployment and to his wife's criticism. He also reported feeling confused and guilty about having these feelings, because from his perspective, he had a good life compared to other people.

\section{Therapists}

Therapists in the York I Depression Study were advanced doctoral candidates or Ph.D.-level clinical psychologists. They had at least two years of specific training and an average of five and half years of therapy experience prior to the beginning of the project. They received an additional 24 weeks of training for the study. The therapists also received weekly supervision during the study, and all demonstrated good adherence to treatment manuals (Greenberg, Rice, \& Elliott, 1993; see Greenberg \& Watson, 1998, for details).

\section{Therapy}

Emotion-focused therapists assume client-centered relational conditions and use experiential and gestalt interventions to facilitate the resolution of maladaptive affective-cognitive processing. These interventions include focusing (Gendlin, 1981) on a marker of an unclear felt sense, systematic evocative unfolding for problematic reactions, two-chair dialogue for self-evaluative and self-interruptive conflict splits, and empty-chair dialogue for unfinished business with a significant other (Greenberg et al., 1993).

\section{Procedure}

The initial step in the analysis involved the identification of IMs types (e.g., action, reflection). This step was done as part of a previous study (Mendes et al., 2010). In the present study, two additional steps were taken. First, protonarratives expressed by the IMs were identified; second, the joint development of IMs and protonarratives throughout therapy was depicted and explored.

\section{Identifying IMs: Coding Procedures and Reliability}

Here, we briefly summarize the procedures used in the Mendes et al. (2010) study. The IMCS (Gonçalves et al., 2011) was used to identify IMs in a sample of EFT therapies in the previous study (Mendes et al., 2010). Two judges who were unaware of the outcome status of the therapies performed this analysis. Judge 1 (fourth author) coded the entire sample (6 cases; 105 sessions), 
and judge 2 (second author) independently coded $50 \%$ of the sessions. Three steps were carried out in the process of coding IMs: (a) a definition of the problems agreed upon by the two raters; (b) identification of each IM, defining its beginning and end; and (c) categorization of previously identified IMs according to their type and the definition of their salience (that is, the proportion of the extension of the IMs compared to the rest of the session; see Mendes et al., 2010 for details). As mentioned, IMCS (Gonçalves et al., 2011) discriminates five types of IMs. Table 1 summarizes the characteristics of each type of IM.

Interjudge agreement on the salience of the IMs was calculated as the overlapping extension of the transcript identified by both judges, divided by the total extension of the transcript identified by either judge (or equivalently, twice the agreed extension spent on IMs divided by the sum of the IM salience independently identified by the two judges). Mendes and colleagues (2010) reported an overall agreement percentage in IM salience of $88.7 \%$ and a reliability for IM type of .86, as assessed by Cohen's kappa, indicating strong agreement between judges (Hill \& Lambert, 2004). Because of the high interjudge reliability, all analyses were based on the coding by Judge 1 .

\section{Identifying Protonarratives: Coding Procedures and Reliability}

We analyzed each IM sequentially and described the protonarrative involved. This step was guided by the question, "What is the potential framework of behaving (acts, thoughts, emotions) present in this IM content?" Note that we assume that problematic self-narratives can be described by implicit rules (e.g., value others' needs and ignore one's own) and, as such, protonarratives may also be described by their implicit organising rules (e.g., you have the right to your feelings). Following the method of constant comparison, rooted in grounded theory analysis (Fassinger, 2005), the protonarrative identified in each IM was compared to the protonarratives previously described to identify convergences and divergences. Whenever strong convergences were found, the new IM was understood to share the previously described protonarrative. When strong divergences were found, a new protonarrative had been formulated. This process ceased when the emergent protonarratives were dense and complex enough to capture all of the variations in the participant's IMs (Fassinger, 2005).

Coding protonarratives in each case involved a discussion between two judges. All judges were doctoral students in clinical psychology. Coding was coupled with an auditing process (Hill et al., 2005) in the following sequence: During meetings, judges discussed the interpretation of the data. Whenever divergences were found, the judges discussed the strengths of each others' interpretations and the criteria used to achieve the interpretations. After the meetings, the judges returned to independent work. Through this interactive procedure, the strengths of each judge were integrated and a consensus was built (Morrow, 2005; Schielke, Fishman, Osatuke, \& Stiles, 2009).

The second and last authors served as external auditors. The auditors were a doctoral student in clinical psychology and an experienced researcher in clinical psychology, both original authors of the IMCS. Their role was one of "questioning and critiquing" (Hill et al., 2005, p. 201) by checking the conceptual sense of the categories and looking for possible better alternatives before delivering this feedback to the judges. This process stopped when the auditors were satisfied with the solutions created by the judges. 


\section{Analysis of IMs and Protonarrative Development}

State space grids (SSGs) were used as a method for the analysis of the IMs and protonarrative development across therapy in both cases. SSGs are a method developed by Marc Lewis and collaborators (Lewis, Lamey, \& Douglas, 1999; Lewis, Zimmerman, Hollenstein, \& Lamey, 2004) for the graphical representation and the quantitative and qualitative analysis of two synchronized categorical time series across time. SSGs have been used in the context of developmental and clinical psychology (see Hollenstein, 2007, for a review). More recently, SSGs have also been applied to the study of narrative innovation in psychotherapy (Ribeiro et al., 2011).

In this study, we took the types of IMs and protonarratives as our basic variables, and a grid was constructed for each therapy session to depict their joint development in both poor-outcome and good-outcome cases. GridWare software (Lamey, Hollenstein, Lewis, \& Granic, 2004) was used for the construction of the grids. As can be seen in Figure 1, in each grid three variables were plotted: the two categorical variables mentioned above (IMs types and protonarratives), on the $x$ and $y$ axes, respectively, and the salience of the IMs was one continuous variable represented by the size of the circles. Each circle in the grid represents a narrative innovation event in the session that is defined both by an IM type and the protonarrative with which it is associated. Lines and arrows in the grids represent the transitions from one IM to the next and the direction of those transitions. The hollow circles represent the first IM of the session. Each row on the grid corresponds to one protonarrative (see Figure 1 for illustrative grids of the cases analysed here).

The longitudinal analysis of each case is given by the analysis of the sequential grids that represent each session of treatment. Three measures were computed for each session in a total of 32 sessions ( 15 sessions from the good-outcome case; 17 sessions from the poor-outcome case): salience, dispersion, and transitions. Healthy self-narratives are thought to be characterized by a balance between narrative content integration and their flexibility (e.g., Singer \& Rexhaj, 2006). Self-narrative integration has typically been associated with the existence of some central and dominant content. Inversely, self-narrative flexibility is associated with the multiplicity of the experiences of which it is composed. This multiplicity relates both to the ability to accommodate diverse and often opposing narrative content and to the ability to make frequent transitions between different contents to enable a person to adaptively face changing demands and situations in everyday life. The three measures that were computed in this study are consistent with these two characteristics of healthy self-narratives: the integrative force of some dominant content (salience) and the flexibility of the available content (dispersion and transitions).

Thus, protonarrative salience was considered to be a measure of dominance and was measured on the basis of the salience of each IM in which it emerged (each dot in each row of the grid). On the basis of SSGs, the relative protonarrative salience for each session was then computed by dividing the extension of each protonarrative (each row) by the total extension of protonarratives in each session (entire SSG) and averaged to obtain the average relative protonarrative salience at the end of therapy.

Dispersion has been considered a reliable indicator of flexibility across the time interval depicted in the grid (Granic, O'Hara, Pepler, \& Lewis, 2007; Hollenstein \& Lewis, 2006). Dispersion is calculated by GridWare according to the formula: $1-[(\mathrm{n} \Sigma(\mathrm{di} / \mathrm{D}) 2)-1] / \mathrm{n}-1$. In the grids, $d i$ is the salience in cell $i, D$ is the total salience of the visited cells, and $n$ is the number of the cells visited. Dispersion varies from 0 to 1 , and low values express concentration in a few types of IMs, whereas high values suggest that protonarratives are distributed throughout several types 


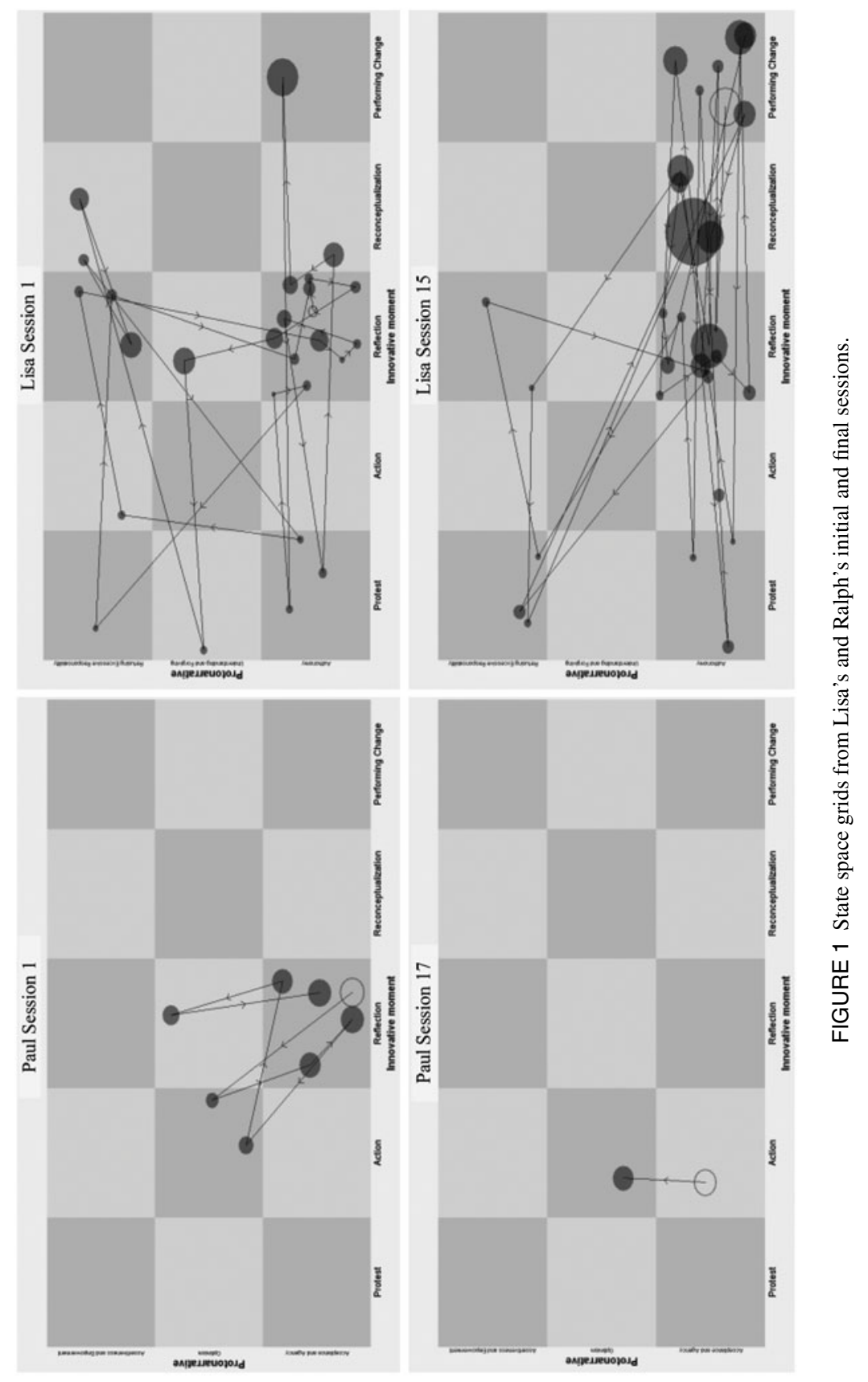


of IMs. Therefore, dispersion is a composite measure that combines the salience and diversity of IMs and protonarratives; it measures flexibility as a function of the distribution of salience through the different IMs types and protonarratives present during each session. Dispersion was calculated both for the entire grid (overall session dispersion) and for each protonarrative (protonarrative dispersion).

Finally, transitions - defined as the amount of interaction between protonarratives and between types of IMs within each protonarrative-were also calculated from the grids. In this sense, the number of transitions between the different IMs and protonarratives gives an index of the ability to flexibly narrate different types of innovative content. Transitions between protonarratives were calculated by counting the number of times an IM in one protonarrative (in one row of the grid) was followed by an IM in another protonarrative (in another row of the grid). Transitions within protonarratives were calculated by counting the number of times an IM in one protonarrative was followed by an IM in the same protonarrative (in the same row) but of a different type (in a different cell). The total number of transitions for each session was computed as the sum of both types of transitions at each session. The average number of transitions was also computed for each case. Both dispersion and the number of transitions between states represented in the SSGs have been shown to be reliable indices of system flexibility (Granic et al., 2007; Hollenstein, Granic, Stoolmiller, \& Snyder, 2004; Hollenstein \& Lewis, 2006).

\section{Analysis of IM and Protonarrative Salience, Dispersion, and Transition}

Simulation Modeling Analysis Software (SMA; Borckardt, 2006; Borckardt et al., 2008) was used to quantitatively analyze the evolution of salience, dispersion, and transitions across the cases. SMA was developed to deal with the statistical problems generated by case-based time series studies by controlling for autocorrelation and a limited number of observations using a bootstrap sampling method (see Borckardt et al., 2008 for technical details). On this basis, changes in the levels of salience, dispersion, and transitions were analyzed across the initial, working, and final therapy phases. Initial and final phases were defined as the first five and last five sessions, respectively. The working phase was considered to be the remaining sessions between the initial and final phases. Spearman rho correlations, computed on the basis of the SMA bootstrap sampling method (Borckardt, 2006; Borckardt et al., 2008), were used.

\section{RESULTS}

\section{How Does Narrative Integration of IMs and Protonarratives Occur Throughout Therapy?}

Both cases revealed the same number of protonarratives, as summarized in Table 2. Figure 1 presents illustrative grids from the initial and final sessions that represent IM and protonarrative evolution across Lisa's and Ralph's treatments, respectively.

The two cases are distinct regarding the protonarratives' salience: While Lisa had one protonarrative that was more salient that the others (autonomy), in Ralph's case, the difference between protonarratives was not as accentuated (see Table 2). As can be seen in Figure 2 (see also Table 2), in Lisa's case, autonomy was the most salient protonarrative throughout therapy and 
TABLE 2

Protonarratives in Lisa's and Ralph's Therapies

\begin{tabular}{|c|c|c|c|c|}
\hline Therapy & Protonarrative & Contents & $\begin{array}{l}\text { Average Relative } \\
\text { Salience } \\
\text { M (SD) }\end{array}$ & $\begin{array}{l}\text { Average } \\
\text { Dispersion } \\
\text { M (SD) }\end{array}$ \\
\hline \multirow[t]{4}{*}{ Lisa } & Autonomy & - Expresses and defends her autonomy. & $.78(.21)$ & $.66(.16)$ \\
\hline & $\begin{array}{l}\text { Understanding and } \\
\text { Forgiving }\end{array}$ & $\begin{array}{l}\text { - Understands the behaviour of others } \\
\text { and forgives. } \\
\text { - Makes a positive synthesis between } \\
\text { positive and negative feelings. }\end{array}$ & $.07(.15)$ & $.05(.09)$ \\
\hline & $\begin{array}{l}\text { Refusing Excessive } \\
\text { Responsibilities }\end{array}$ & $\begin{array}{l}\text { - Stops assuming responsibility for the } \\
\text { behaviour of others. }\end{array}$ & $.15(.17)$ & $.47(.19)$ \\
\hline & (Total Dispersion) & $\longrightarrow$ & - & $.71(.09)$ \\
\hline \multirow[t]{4}{*}{ Ralph } & Acceptance and agency & $\begin{array}{l}\text { - Understands the problem and acts in } \\
\text { accordance. }\end{array}$ & $.36(.29)$ & $.12(.21)$ \\
\hline & Optimism & - Optimism and hopefulness. & $.24(.24)$ & $.23(.30)$ \\
\hline & $\begin{array}{l}\text { Assertiveness and } \\
\text { empowerment }\end{array}$ & $\begin{array}{l}\text { - Assertiveness and self-confidence. } \\
\text { - Refusal of wife's criticism. }\end{array}$ & $.28(.28)$ & $.15(.19)$ \\
\hline & (Total Dispersion) & - & - & $.54(.22)$ \\
\hline
\end{tabular}

was also consistently present in every session of treatment. Understanding and forgiving revealed a residual presence (these were only present in five sessions) and low salience across sessions. Refusing excessive responsibility had an intermediate salience and presence (it appeared in 11 sessions). Autonomy relative salience showed a significant increase from the initial $(M=.63$, $S D=.19)$ to the working $(M=.82, S D=.16)$ phases $(r h o=.45, p=.05)$. The relative salience of the other two protonarratives (refusing excessive responsibilities and understanding and forgiving) revealed no significant change throughout therapy phases.

This contrasts with the observed development of protonarratives across Ralph's treatment, in which the protonarratives were not as differentiated as Lisa's, either in terms of average relative salience (see Table 2) or in terms of frequency of occurrences in different sessions (acceptance and

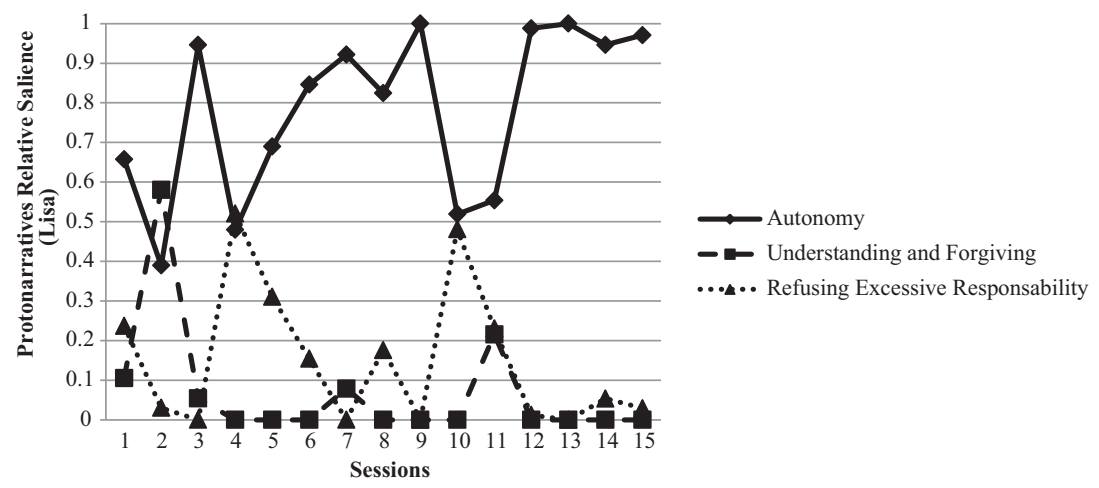

FIGURE 2 The relative salience of Lisa's protonarratives. 


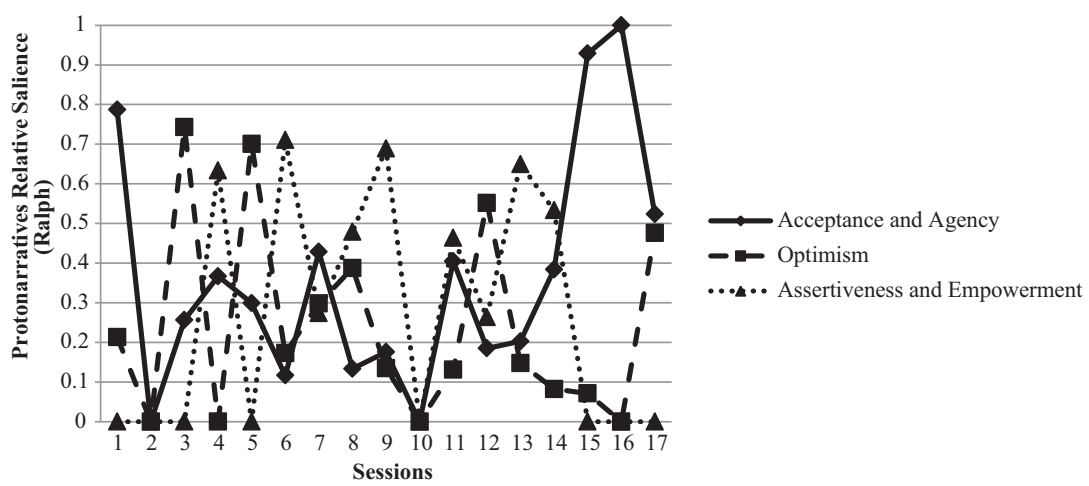

FIGURE 3 The relative salience of Ralph's protonarratives.

agency was present in 15 sessions, optimism in 13 sessions, and assertiveness and empowerment in 9 sessions). The analysis of Figure 3 revealed that the relative saliences of acceptance and agency significantly increased from the working $(M=.21, S D=.14)$ to the final phases $(M=.61$, $S D=31 ; r h o=.66, p=.03)$. The relative salience of optimism revealed no significant changes across therapy. The relative salience of assertiveness and empowerment revealed a significant increase from the initial sessions $(M=.13, S D=.25)$ to the working sessions $(M=.41, S D=$ .23 ; $r h o=.53, p=.01)$.

Overall, the analysis of Table 2 and Figures 2 and 3 reveals that in Lisa's therapy, all protonarratives were present from the first session. The most salient protonarrative at that session was also the one that showed higher salience at the end of therapy. In Ralph's therapy, the protonarratives were not all present from the first session, but the most salient protonarrative at the first session had high salience at the end of therapy.

\section{How Does the Flexibility of IMs and Protonarratives Evolve Throughout Therapy?}

\section{Protonarrative Dispersion}

Overall dispersion was lower in Ralph's than in Lisa's therapy. Lisa's autonomy protonarrative was the most dispersed, followed by refusing excessive responsibility and understanding and forgiving (see Table 2). The evolution of protonarrative dispersion across treatment is depicted in Figure 4.

Lisa's overall dispersion revealed moderate values across the initial, working, and final sessions (see Table 2), without significant changes across these phases. In relation to the dispersion of autonomy, a significant increase was observed from the initial sessions $(M=.5, S D=.17)$ to the working sessions $(M=.72, S D=.09$; rho $=.66, p=.01)$. The evolution of dispersion for the other protonarratives was not analyzed due to the reduced number of sessions in which dispersion was computed (note that dispersion is impossible to compute in sessions in which protonarrative salience is 0 ). 


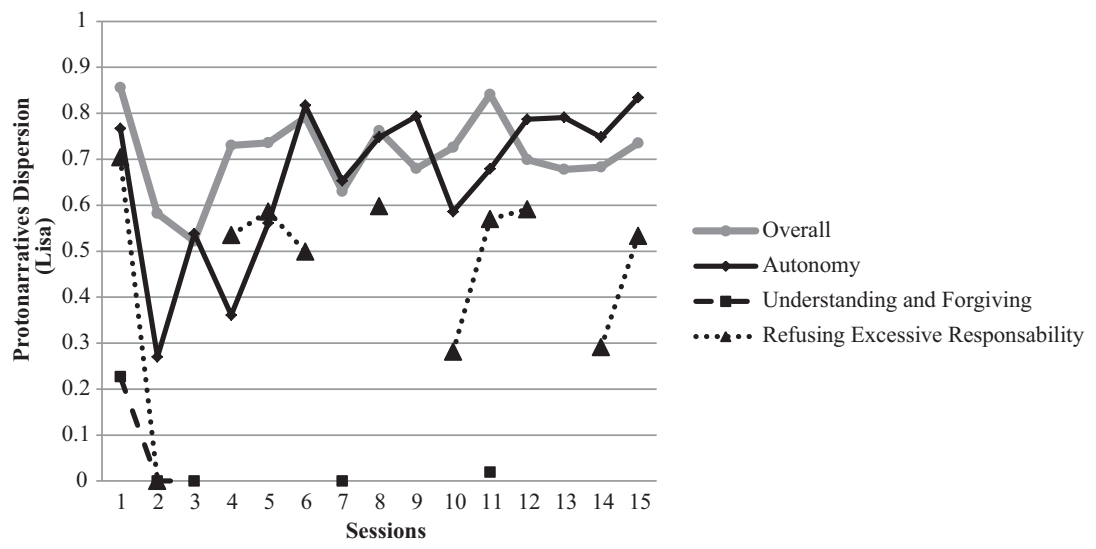

FIGURE 4 The dispersion of Lisa's protonarratives.

Ralph's most dispersed protonarrative was optimism followed by assertiveness and empowerment and acceptance and agency (see Table 2). The evolution of dispersion for these protonarratives across therapy is depicted in Figure 5. Ralph's overall dispersion revealed a significant increase from the initial $(M=.42, S D=.24)$ to the working $(M=.57, S D=.25)$ phase (rho= $.66, p=.01)$. Analysis of the evolution of the different protonarratives was not pursued due to the low number of sessions in which dispersion was computed.

\section{Protonarrative Transitions}

Table 3 presents the number of transitions within and between protonarratives in both cases. Compared to Ralph, Lisa had more frequent transitions between and within protonarratives as well as a greater total number of transitions. Moreover, Lisa showed a higher number of transitions

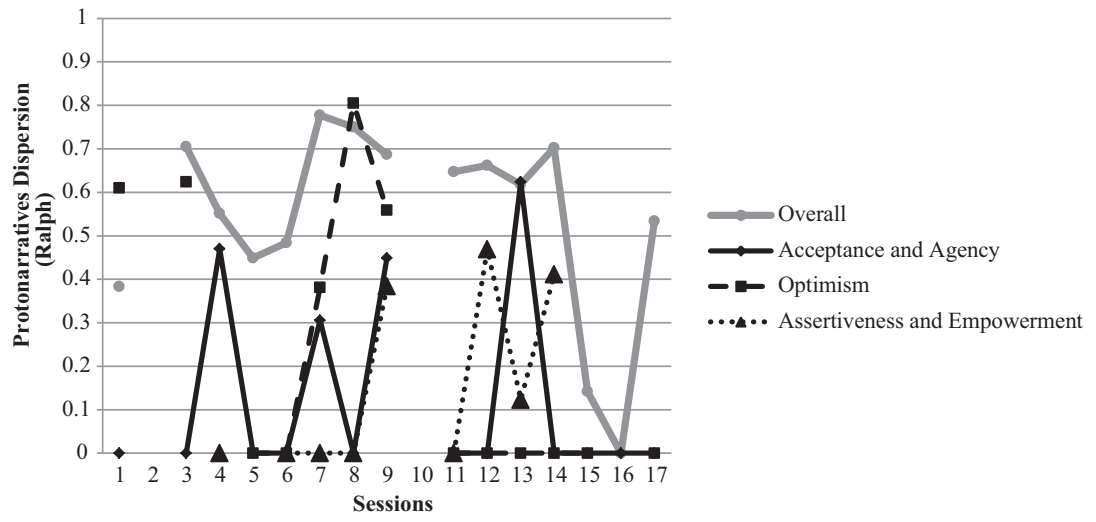

FIGURE 5 The dispersion of Ralph's protonarratives. 
TABLE 3

Lisa's and Ralph's Transitions

\begin{tabular}{|c|c|c|c|c|c|}
\hline \multirow[b]{2}{*}{ Therapy } & \multirow[b]{2}{*}{ Measure } & \multicolumn{3}{|c|}{ Therapy Phases } & \multirow[b]{2}{*}{$\begin{array}{l}\text { Overall } \\
\mathrm{M}(\mathrm{SD})\end{array}$} \\
\hline & & $\begin{array}{c}\text { Initial } \\
M(S D)\end{array}$ & $\begin{array}{l}\text { Working } \\
\text { M (SD) }\end{array}$ & $\begin{array}{c}\text { Final } \\
\mathrm{M}(\mathrm{SD})\end{array}$ & \\
\hline \multirow[t]{3}{*}{ Lisa } & Transitions within protonarratives & $7(3.9)$ & $9.8(3.49)$ & $12(6.48)$ & $9.6(5.23)$ \\
\hline & Transitions between protonarratives & $5.2(1.94)$ & $4.2(2.64)$ & $5(2.97)$ & $4.8(2.59)$ \\
\hline & Total number of transitions & $12.2(4.3)$ & $14(5.02)$ & $17(6.96)$ & $14.4(5.89)$ \\
\hline \multirow[t]{3}{*}{ Ralph } & Transitions within protonarratives & $.4(.49)$ & $1.57(2.19)$ & $.4(.49)$ & $.88(1.57)$ \\
\hline & Transitions between protonarratives & $3(2)$ & $4(2.07)$ & $2.2(1.47)$ & $3.18(2.04)$ \\
\hline & Total number of transitions & $3.4(2.15)$ & $5.57(3.66)$ & $2.6(1.85)$ & $4.06(3.1)$ \\
\hline
\end{tabular}

within protonarratives than between protonarratives. The opposite pattern was observed in Ralph's therapy.

The evolution of the number of transitions between and within protonarratives in Lisa's and Ralph's therapies is depicted in Figures 6 and 7, respectively. In both cases, the total number of transitions and the number of transitions between and within protonarratives did not change significantly throughout treatment.

\section{DISCUSSION}

Despite having the same number of protonarratives, important differences in the development of each of the cases across treatment were observed. It was found that in the good-outcome case, there is a higher degree of dispersion of the different IM types and protonarratives than in the poor-outcome case. An increased ability to make frequent transitions between the different

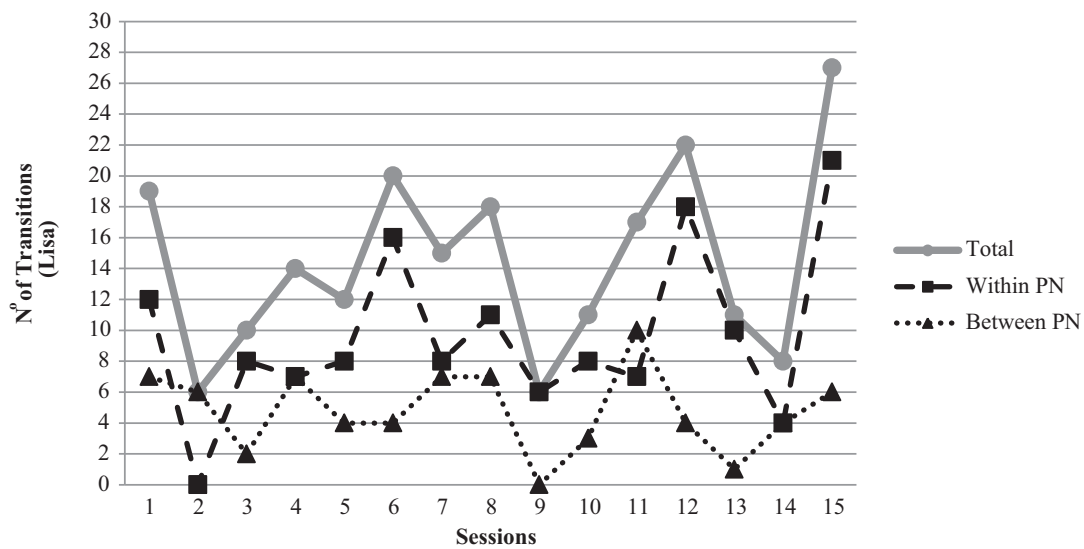

FIGURE 6 Lisa's transitions between and within protonarratives. 


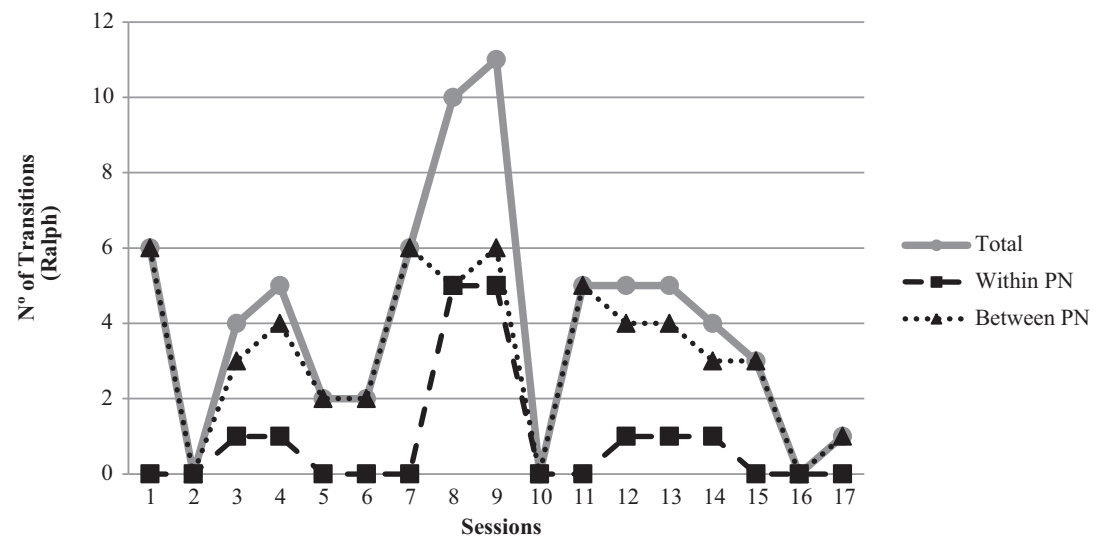

FIGURE 7 Ralph's transitions between and within protonarratives.

components of narrative innovation is also present in the good-outcome compared to the pooroutcome case. Taken together, these two results suggest that the process of narrative innovation is more flexible in the good- than in the poor-outcome case. Moreover, in the good-outcome case, one of the protonarratives is dominant throughout the therapeutic process, and this seemed to be more accentuated in the working and final phases of therapy. Globally, this dominant protonarrative reveals not only higher salience but also higher dispersion than the other protonarratives. Moreover, the salience and dispersion of this dominant protonarrative increase significantly from the initial to the working phases, and these higher values are maintained in the final sessions. These results seem consistent with a process of development and consolidation around one central protonarrative that organizes the alternative self-narrative and around which further IMs become aggregated. In fact, in the good-outcome case, this dominant protonarrative is elaborated for significant periods of time. As observed, in the good-outcome case, the number of transitions between IMs within this protonarrative is consistently more frequent than the number of transitions between protonarratives. We hypothesize that this process of recurrently focusing on the same innovative content (protonarrative) while varying the processes of narrative innovation (IMs) may help explain the expansion and the increase in complexity, diversity, and dominance of one protonarrative. Thus, globally, the good-outcome case reveals a pattern of high flexibility associated with the dominance of one protonarrative. This pattern is consistent with what was suggested to be the features of adaptive self-narratives as described by Singer and Rexhaj (2006) and also by McAdams (2006). In fact, these researchers equated narrative adaptation both with coherence and flexibility.

This pattern seems to contrast with the pattern that was observed in the poor-outcome case, in which the therapeutic dialogue is scattered around different protonarratives without any assuming clear dominance. The different protonarratives have similar average salience and dispersion, suggesting that this lack of dominance is important. Additionally, significant changes in the relative salience of the protonarratives occurred from one phase of the therapy to the next, with different protonarratives dominating in different phases. This is associated with a consistent tendency for the number of transitions between protonarratives to be more frequent than the 
number of transitions within protonarratives. Furthermore, the development of protonarratives, in terms of salience, is not followed by an increase in their flexibility. In fact, protonarratives with higher salience appear to be associated with lower dispersion. Globally, constant changes between protonarratives that are associated with relative rigidity seem to have prevented a dominant protonarrative from emerging as a central organizing framework for the alternative self-narrative. Thus, we suggest that in the poor-outcome case, the instability of the protonarratives may have contributed to blocking further change.

One interesting result is that in the good-outcome case, all of the protonarratives were present from the first session. This contrasts with a previous case study (Ribeiro et al., 2011) in which a good-outcome case revealed a more progressive development of protonarratives characterized by the emergence of more complex protonarratives over the course of therapy. This observation suggests that it could be important to further explore the possibility that protonarrative development in good-outcome cases may follow different patterns. Future research should also explore the contribution of clients' characteristics and therapeutic strategies for such differences.

The observations from the poor-outcome case suggest that in such cases, the dominant protonarrative may be unable to organize the alternative narrative in a consistent manner. This is consistent with previous results which show that poor outcomes are associated with low frequency and salience of IMs (Gonçalves et al., 2012; Matos et al., 2009; Mendes et al., 2010), which poses obstacles for the development of salient and flexible protonarratives.

Although the processes that contribute to the underdevelopment of the potentially organizing protonarrative are unclear, it seems reasonable to hypothesize that the relative inconsistency of thematic content of IMs may contribute to this outcome. Two observations are congruent with this hypothesis: the accentuated oscillations in the protonarrative salience from session to session, and the fact that there are consistently fewer transitions within protonarratives than between protonarratives in the poor-outcome case. As discussed above, thematic content appears and disappears from the therapeutic dialogue, as clients frequently change between protonarratives and seldom remain focused on the same theme.

These were only two intensive case studies and, naturally, further efforts should be made to support these hypotheses and explore new ones related to the narrative model of therapeutic change. It remains unclear whether the developmental patterns displayed by these two cases are generalizable. The measurement of the properties of self-narratives that were focused on in this study should also be pursued with alternative methods. Although the measures of narrative flexibility used here are independent from the theoretical framework of the study, to some extent there may be interdependence between them. Additionally, studying the evolution of these measures by comparing therapy phases may have masked the more detailed variations and fluctuations of these measures. Therefore, not only alternate measurement techniques are advisable but also the exploration of other characteristics of the evolution of flexibility across therapy is advised. Despite these limitations, this study agrees with our general assumptions related to the process by which meaning rigidity of problematic self-narratives is first destabilized and next replaced by an alternative, more diversified, and more complex system of meanings.

Clinically, this study adds to the increasing amount of research that suggests the need for therapists to be alert to the potentially innovative meanings and actions that contrast with the influence of problematic self-narratives and their ways of thinking, feeling, and behaving, in the context of an alternative meaning. In fact, despite the exploratory nature of this study, it seems 
to suggest that integration and flexibility are two crucial characteristics of alternative, adaptive self-narratives.

\section{REFERENCES}

Angus, L., Goldman, R., \& Mergenthaler, E. (2008). Introduction. One case, multiple measures: An intensive caseanalytic approach to understanding client change processes in evidence-based emotion focused therapy of depression [Special issue]. Psychotherapy Research, 6, 629-633.

Beck, A., Steer, R., \& Garbin, M. (1988). Psychometric properties of the Beck Depression Inventory: Twenty-five years of evaluation. Clinical Psychology Review, 8, 77-100.

Borckardt, J. (2006). Simulation modeling analysis: Time series analysis program for short time series data streams [Computer software].

Borckardt, J., Nash, M., Murphy, M., Moore, M., Shaw, D., \& O’Neil, P. (2008). Clinical practice as natural laboratory for psychotherapy research. American Psychologist, 63, 77-95.

Dimaggio, G., \& Semerari, A. (2001). Psychopathological narrative forms. Journal of Constructivist Psychology, 14, $1-23$.

Dimaggio, G., Salvatore, G., Azzara, C., Catania, D., Semerari, A., \& Hermans, H. (2003). Dialogical relationships in impoverished narratives: From theory to clinical practice. Psychology and Psychotherapy: Theory, Research and Practice, 76, 385-409.

Fassinger, R. (2005). Paradigms, praxis, problems, and promise: Grounded theory in counseling psychology research. Journal of Counseling Psychology, 52, 156-166.

Gendlin, E. T. (1981). Focusing (2nd ed.). New York: Bantam Books.

Gonçalves, M. (2012). Innovative moments in cognitive-behavioral therapy. Manuscript in preparation,

Gonçalves, M., Matos, M., \& Santos, A. (2009). Narrative therapy and the nature of "innovative moments" in the construction of change. Journal of Constructivist Psychology, 22, 1-23.

Gonçalves, M., Mendes, I., Ribeiro, A., Angus, L., \& Greenberg, L. (2010). Innovative moments and change in emotional focused therapy: The case of Lisa. Journal of Constructivist Psychology, 23, 1-28.

Gonçalves, M. M., Mendes, I, Cruz, G., Ribeiro, A. P., Angus, L. E., \& Greenberg, L. S. (2012). Innovative moments and change in client-centered therapy. Psychotherapy Research, 22, 389-401.

Gonçalves, M., Ribeiro, A., Matos, M., Mendes, I., \& Santos, A. (2011). Tracking novelties in psychotherapy research process: The Innovative Moments Coding System. Psychotherapy Research, 21, 497-509.

Gonçalves, M., \& Stiles, W. B. (2011). Narrative and psychotherapy: Introduction to the special section. Psychotherapy Research, 21, 1-3.

Granic, I., O’Hara, A., Pepler, D., \& Lewis, M. (2007). A dynamic system analysis of parent-child changes associated with successful "real-world" interventions of aggressive children. Journal of Abnormal Child Psychology, 35, 606-617.

Greenberg, L. \& Watson, J. (1998). Experiential therapy of depression: Differential effects of client-centered relationship conditions and process experiential interventions. Psychotherapy Research, 8, 210-224.

Greenberg, L., Rice, L., \& Elliott, R. (1993). Facilitating emotional change: The moment-by-moment process. New York: Guilford.

Hermans, H. (2006). The self as a theater of voices: Disorganization and reorganization of a position repertoire. Journal of Constructivist Psychology, 19, 147-169.

Hollenstein, T. (2007). State space grids: Analyzing dynamics across development. International Journal of Behavioral Development, 31, 384-396.

Hollenstein, T., \& Lewis, M. (2006). A state space analysis of emotion and flexibility in parent-child interactions. Emotion, $6,656-662$.

Hollenstein, T., Granic, I., Stoolmiller, M., \& Snyder, J. (2004). Rigidity of parent-child interactions and the development of externalizing and internalizing behavior in early childhood. Journal of Abnormal Child Psychology, 32, 595-607.

Hill, C., \& Lambert, M. (2004). Methodological issues in studying psychotherapy processes and outcomes. In M. J. Lambert (Ed.), Bergin and Garfield's handbook of psychotherapy and behavior change (5th ed., pp. 84-135). New York: Wiley.

Hill, C., Knox, S., Thompson, B., Nutt Williams, E., Hess, S., \& Ladany, N. (2005). Consensual qualitative research: An update. Journal of Counseling Psychology, 52, 196-205. 
Jacobson, N., \& Truax, P. (1991). Clinical significance: A statistical approach to defining meaningful change in psychotherapy research. Journal of Consulting and Clinical Psychology, 59, 12-19.

Lamey, A., Hollenstein, T., Lewis, M., \& Granic, I. (2004). GridWare (version 1.1). [Computer software]. http: //statespacegrids.org.

Lewis, M., Lamey, A., \& Douglas, L. (1999). A new dynamic systems method for the analysis of early socioemotional development. Developmental Science, 2, 458-476.

Lewis, M., Zimmerman, S., Hollenstein, T., \& Lamey, A. (2004). Reorganization in coping behavior at $1 \frac{1}{2}$ years: Dynamic systems and normative change. Developmental Science, 7, 56-73.

Lysaker, P., \& Lysaker, P. (2006). A typology of narrative impoverishment in schizophrenia: Implications for understanding the process of establishing and sustaining dialogue in individual psychotherapy. Counseling Psychology Quarterly, $19,57-68$.

Matos, M., Santos, A., Gonçalves, M., \& Martins, C. (2009). IMs and change in narrative therapy. Psychotherapy Research, 19, 68-80.

McAdams, D. (2006). The problem of narrative coherence. Journal of Constructivist Psychology, 19, 109-125.

McAdams, D. P. (1996). Personality, modernity, and the storied self: A contemporary framework for studying persons. Psychological Inquiry, 7, 295-321.

McGlinchey, J., Atkins, D., \& Jacobson, N. (2002). Clinical significance methods: Which one to use and how useful are they?. Behavior Therapy, 33, 529-550.

Meier, A. (2002). Narrative in psychotherapy theory, practice, and research: A critical review. Counseling and Psychotherapy Research, 2, 239-251.

Mendes, I., Ribeiro, A., Angus, L., Greenberg, L., Sousa, I., \& Gonçalves, M. (2010). Narrative change in emotion-focused therapy: How is change constructed through the lens of the Innovative Moments Coding System? Psychotherapy Research, 20, 692-701.

Morrow, S. (2005). Quality and trustworthiness in qualitative research in counseling psychology. Journal of Counseling Psychology, 52, 250-260.

Neimeyer, R. (2004). Fostering posttraumatic growth: A narrative contribution. Psychological Inquiry, 15, 53-59.

Ribeiro, A., Bento, T., Gonçalves, M., \& Salgado, J. (2010). Self-narrative reconstruction in psychotherapy: Looking at different levels of narrative development. Culture and Psychology, 16, 195-212.

Ribeiro, A., Bento, T., Salgado, J., Stiles, W., \& Gonçalves, M. (2011). A dynamic look at narrative change in psychotherapy: A case-study tracking IMs and protonarratives using state-space grids. Psychotherapy Research, 21, 54-69.

Ribeiro, A., Gonçalves, M., \& Ribeiro, E. (2009). Processos narrativos de mudança em psicoterapia: Estudo de um caso de sucesso de terapia construtivista [Narrative change in psychotherapy: A good outcome case of constructivist therapy]. Psychologica, 50, 181-203.

Schielke, H., Fishman, J., Osatuke, K., \& Stiles, W. (2009). Creative consensus on interpretations of qualitative data: The Ward method. Psychotherapy Research, 19, 558-565.

Singer, J., \& Rexhaj, B. (2006). Narrative coherence and psychotherapy: A commentary. Journal of Constructivist Psychology, 19, 207-217.

Singer, J., Blagov, P., Berry, M., \& Oost, K. (2013). Self-defining memories, scripts, and the life story: Narrative identity in personality and psychotherapy. Journal of Personality. DOI: 10.1111/jopy.12005 [Epub ahead of print].

Spitzer, R., Williams, J., Gibbons, M., \& First, M. (1989). Structured clinical interview for DSM-III-R. Washington, DC: American Psychiatric Association. 